\title{
Optimization of Lactic Acid Production from Pineapple By- Products and an Inexpensive Nitrogen Source Using Lactiplantibacillus plantarum strain 408
}

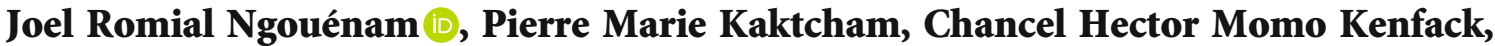 \\ Edith Marius Foko Kouam, and François Zambou Ngoufack
}

Research Unit of Biochemistry, Medicinal Plants, Food Science and Nutrition (URBPMAN) Department of Biochemistry, Faculty of Science, University of Dschang, P.O. Box 67, Dschang, Cameroon

Correspondence should be addressed to Joel Romial Ngouénam; ndeffothomas@yahoo.fr

Received 17 May 2021; Revised 12 September 2021; Accepted 28 September 2021; Published 19 October 2021

Academic Editor: Ivan Salmerón

Copyright ( 92021 Joel Romial Ngouénam et al. This is an open access article distributed under the Creative Commons Attribution License, which permits unrestricted use, distribution, and reproduction in any medium, provided the original work is properly cited.

\begin{abstract}
Lactic acid (LA) is used in food, cosmetic, chemical, and pharmaceutical industries and has recently attracted much attention in the production of biodegradable polymers. The expensive substances including carbon and nitrogen sources involved in its fermentative synthesis and the increasing market demand of LA have prompted scientists to look for inexpensive raw materials from which it can be produced. This research was aimed at determining the optimum conditions of lactic acid (LA) production from pineapple by-products and an inexpensive nitrogen source using Lactiplantibacillus plantarum strain 408 . After collection and preparation of the carbon source (pineapple by-products) and nitrogen sources (by-products from fish, chicken, and beer brewing industries), they were used for the formulation of 4 different media in terms of nitrogen sources. Then, the proximate compositions of promising nitrogen sources were determined. This was followed by the screening of factors (temperature, carbon source, nitrogen source, $\mathrm{MgSO}_{4}, \mathrm{MnSO}_{4}, \mathrm{FeSO}_{4}, \mathrm{KH}_{2} \mathrm{PO}_{4}$, and $\mathrm{KHPO}_{4}$ ) influencing the production of LA using the definitive plan. Lastly, the optimization process was done using the central composite design. The highest LA productions $(14.64 \pm 0.05 \mathrm{~g} / \mathrm{l}$ and $13.4 \pm 0.02 \mathrm{~g} / \mathrm{l})$ were obtained in production medium supplemented with chicken and fish by-products, respectively, making them the most promising sources of nitrogen. The proximate analysis of these nitrogen sources revealed that their protein contents were $83.00 \pm 1.41 \% \mathrm{DM}$ and $74.00 \pm 1.41 \% \mathrm{DM}$ for chicken by-products and fish by-products, respectively. Concerning the screening of factors, temperature, nitrogen source, and carbon source were the factors that showed a major impact on LA production in the production medium containing chicken by-products as nitrogen source. A pineapple by-product concentration of $141.75 \mathrm{~g} / \mathrm{l}$, a nitrogen source volume of $108.99 \mathrm{ml} / \mathrm{l}$, and a temperature of $30.89^{\circ} \mathrm{C}$ were recorded as the optimum conditions for LA production. The optimization led to a 2.73 -fold increase in LA production when compared with the production medium without nitrogen source. According to these results, chicken by-products are a promising and an inexpensive nitrogen source that can be an alternative to yeast extract in lactic acid production.
\end{abstract}

\section{Introduction}

Many substances which contribute to human well-being result from microorganism's exploitation; LA is concerned [1]. It is an important chemical that can be produced by lactic acid bacteria for many potential applications. LA has applications in pharmaceutical (dialysis solution, min- eral preparations, tableting, surgical sutures, and prosthesis), chemical ( $\mathrm{pH}$ regulators, chiral intermediates, cleaning agent, metal complexing agents, and green solvent), food (acidulant, flavor enhancer, preservatives, mineral fortification, and antioxidant), and cosmetic (antitartar agents, antiacne agents moisturizers, skin-lightening agents, skin rejuvenating agents, and humectants); it is 
also used in the biodegradables polymers production [2, 3]. The global LA market is not insignificant; indeed, it will increase from 1220.0 kilotons in 2016 to 1960.1 kilotons in 2025 and represent a turnover of about 9.8 billion dollars [3]. LA can be produced by chemical synthesis or fermentation. In recent years, the fermentation approach has become more successful; 95\% of industrial production of LA is obtained by fermentation pathway since this natural way generates optically pure lactate, and also, byproducts from this process do not pollute the environment [4-7]. However, this natural way of producing LA has a real production cost problem caused by the use of expensive substrates, especially carbon sources (glucose, sucrose, lactose, and maltose) and also nitrogen sources (yeast extract, ammonium sulphate, and peptone) [4]. Furthermore, the availability of LA and also its accessibility for the various applications in the different aforementioned industries would thus be limited. It is therefore essential to search for alternatives to these expensive substrates. Indeed, the production medium plays an important part in the cost of producing biomass, metabolites, and therefore LA; it is consequently essential to find a balance between the nutritional and the technological qualities of the raw materials, their prices, and their availability. Thus, by-products from the food industry with regard to their carbohydrate and protein composition [4, 8-10] could contribute to reducing the costs involved in the production of lactic acid by the fermentation way. Several scientific studies have focused on the use of by-products from food industry as a carbon source (molasses, fruit by-products, whey, cassava bagasse, starch, sweet sorghum juice, and lignocellulose biomass) $[3,7,11-15]$ and also as a nitrogen source (corn steep liquor, malt buds, red lentil, and baker's yeast cells) for the LA production $[4,16$, 17]. However, the use of by-products from the processing and marketing chain of fish, chicken, and beer industries production as a nitrogen source in a production medium containing pineapple by-products as a carbon source is still unknown to the scientific community.

The objective of the present study was to determine the optimum conditions of lactic acid production from pineapple by-products and an inexpensive nitrogen source using Lactobacillus plantarum $4 \mathrm{O} 8$ strain.

\section{Materials and Methods}

2.1. Bacterial Strain, Media, and Growth Conditions. The Lactiplantibacillus plantarum strain 408 used in this study was obtained from our research unit collection. This strain was isolated from orange sold in Dschang city during our previous studies [10] and identified by $16 \mathrm{~S}$ rRNA gene sequencing and its sequence deposited in the NCBI GenBank under the accession number MW164849. This strain was selected as a good fermenter of pineapple by-products. The reactivation $(1 \% v / v)$ of the strain was carried out in the previously sterilized MRS broth (TM MEDIA, Titan Biotech Ltd, India) medium from the stored culture which was kept at $-20^{\circ} \mathrm{C}$ in the reconstituted skim milk $(12.5 \%(w / v)$ supplemented with 25\% $(v / v)$ glycerol [18]. After 12 hours of growth at $30^{\circ} \mathrm{C}$, the strain was used for further work.

\subsection{Preparation and Chemical Composition of Carbon Source}

2.2.1. Chemical Composition of Carbon Source. Previous work [10] showed the chemical proximate composition of pineapple by-products (carbon source).

2.2.2. Preparation of Carbon Source. Pineapple by-products were collected at the central market of the city of Dschang and sent to the laboratory for further processing. The modified method of Mudaliyar et al. [11] was used for the preparation of carbon sources. Five hundred grams $(500 \mathrm{~g})$ of these substrates was steam treated in an autoclave (Sonoclav) at $121^{\circ} \mathrm{C}$ for 20 minutes. Once cooled, distilled water was added to our substrate to make a volume of 11 and was then boiled at $80^{\circ} \mathrm{C}$ for 30 minutes in a water bath (HH-W420, China). Finally, the hydrolysate was recovered by filtration using a cotton veil and acid hydrolysis of the filtrate obtained previously was carried out by autoclaving it at $121^{\circ} \mathrm{C}$ with $1 \%(v / v) 2 \mathrm{M} \mathrm{HCl}$ for $20 \mathrm{~min}$. The $\mathrm{pH}$ of the hydrolysate obtained was adjusted to a value of 6.6 with $\mathrm{CaO}$, and the $\mathrm{CaSO}_{4}$ precipitate formed was removed by filtration with Whatman filter paper No.1.

\subsection{Preparation and Proximate Analysis of Nitrogen Sources}

\subsubsection{Preparation of Nitrogen Sources}

(1) Source of Nitrogen from Chicken (BC) and Fish (BF). Nitrogen sources were prepared following the method described by Ben et al. [19] with modifications. The fish by-products consisted of heads, viscera, bones, and muscle residues. Concerning the chicken by-products, they consisted of chicken intestines, pancreas, heart-lung, and their heads. All these nitrogen sources were aseptically collected in sterile coolers in fish shops and poultry slaughterhouses of the central market of the city of Dschang (Menoua Division, West Cameroon region). They were transported to the laboratory where they were subjected to various treatments. After cleaning, fish and chicken by-products were minced by a blender, mixed with sterile water $(500: 1 \mathrm{~g} / 1)$, and heated at $100^{\circ} \mathrm{C}$ for 20 minutes. After this heat pretreatment, the insoluble material was removed by centrifugation (4500 rpm for $30 \mathrm{~min}$ ), and the supernatant (BF and BC) was collected and kept at $4^{\circ} \mathrm{C}$ until further use.

(2) Source of Nitrogen from the Beer Production Industry $(B B I P)$. In the beer production industries in Cameroon, the dead cells of Saccharomyces cerevisiae resulting from the fermentation and which constitute a source of protein [20] are mixed with dregs to enrich it before being made available to the various users. Dregs, a by-product of these industries, were aseptically collected in sterile coolers in the Cameroon Brewery company of the city of Bafoussam (Mifi Division, West Cameroon region) and transported to the laboratory. The preparation of the nitrogen source from this byproduct was carried out as described by Zarei et al. [20]. Five 
hundred grams $(500 \mathrm{~g})$ of this by-product was introduced into 21 of distilled water, and then the whole was heat treated by autoclaving $\left(121^{\circ} \mathrm{C}, 15 \mathrm{~min}, 1.2 \mathrm{bar}\right)$ and followed by quenching in an ice bath. The insoluble material was then removed by centrifugation ( $4500 \mathrm{rpm}$ for $30 \mathrm{~min}$ ), and the supernatant was collected. Finally, the previously collected supernatant was again subjected to the two treatments mentioned above (autoclaving and centrifugation), and the new supernatant (BBIP) was collected and kept at $4^{\circ} \mathrm{C}$ until further use.

2.3.2. Proximate Analysis of Nitrogen Sources. According to the methods described by IUPAC [21] and AOAC [22], the proximate composition (fat, protein, ash, $\mathrm{P}, \mathrm{Ca}, \mathrm{Mg}$, $\mathrm{Na}, \mathrm{Mn}, \mathrm{Fe}, \mathrm{Zn}$, and $\mathrm{K}$ ) of nitrogen sources was assessed.

\subsection{Preparation of the Inoculum and Fermentation} Conditions. The modified method of Herdian et al. [23] was used for the preparation of the inoculum. Young ( $12 \mathrm{~h}$-old cultures) cultures were streaked on previously cast and solidified MRS agar. The inoculated medium was incubated for $48 \mathrm{~h}$. Then, the bacteria were aseptically collected from the surface of the agar and suspended in $10 \mathrm{ml}$ of a sterile $\mathrm{NaCl}$ solution $(0.9 \%)$. The mixture was then vortex agitated and its opacity adjusted to McFarland's scale 2. The cell suspension corresponding to McFarland scale 2 (approximately $6 \times 10^{8} \mathrm{CFU} / \mathrm{ml}$ ) was used as inoculum for the fermentation.

Batch cultures were carried out in $250 \mathrm{ml}$ Erlenmeyer units with a useful volume of $100 \mathrm{ml}$ of the supplemented and sterile hydrolysate. The synthetic medium for the fermentation was prepared using Mudaliyar et al.'s [11] method with modification: hydrolysate: $1000 \mathrm{ml}$; nitrogen: $60 \mathrm{ml}$; sodium acetate: $5 \mathrm{~g} ; \mathrm{MgSO}_{4} .7 \mathrm{H}_{2} 0: 0.6 \mathrm{~g} ; \mathrm{MnSO}_{4} \cdot \mathrm{H}_{2} \mathrm{O}$ : $0.05 \mathrm{~g} ; \mathrm{K}_{2} \mathrm{HPO}_{4}: 0.8 \mathrm{~g} ; \mathrm{KH}_{2} \mathrm{PO}_{4}: 0.8 \mathrm{~g}$; and $\mathrm{FeSO}_{4}: 0.05 \mathrm{~g}$. Then, this fermentation medium was inoculated at a rate of $5 \%(v / v)$ and incubated at $30^{\circ} \mathrm{C}$ under agitation after every $2 \mathrm{~h}$ for 2 days. Substrate consumption and lactic acid production were determined on a regular time range $(0,8,16$, 24,32 , and $48 \mathrm{~h}$ ).

\subsection{Estimation of Reducing Sugars Consumption and Lactic} Acid Production in the Production Medium. Using DNS (3,5-dinitro salicylic acid) method as described by Fisher and Stein [24], the residual reducing sugar content of the production medium was estimated on regular basis spectrophotometrically. The results obtained were the mean of three experiments.

The spectrophotometric method described by Borshchevskaya et al. [25] was used for lactic acid quantification. One $\mathrm{ml}$ of the fermentation broth was centrifuged (4500 rpm for $30 \mathrm{~min}$ ), and the supernatant was collected and diluted 10 times. Subsequently, $0.1 \mathrm{ml}$ of the previous dilution was added to $4 \mathrm{ml}$ of a $\mathrm{FeCl} 3$ solution (0.2\%); after homogenization, the optical density was measured with a spectrophotometer (Thermo Scientific BioMate $3 \mathrm{~S} \mathrm{UV-}$ Visibles spectrophotometer, Thermo Scientific, USA) at a wavelength of $390 \mathrm{~nm}$. Based on a previously drawn calibra- tion curve, the amount of lactic acid was calculated. The experiments were repeated three times.

2.6. Screening for the most Significant Factors Influencing LA Production by Definitive Design. A definitive plan was used for the screening of factors influencing LA production. Based on the literature and previous works, 8 factors were chosen including nitrogen source, carbon source, temperature, magnesium sulphate, dipotassium phosphate, monopotassium phosphate, manganese sulphate, and ferrous sulphate; the time was kept constant $(16 \mathrm{~h})$. The intervals of these different factors are summarized in Table 1. A total number of 17 experimental runs (Table 2) were obtained, and LA production was used as response. The number of tests was determined by applying the formula $2 k+1$ with $k$ representing the number of factors. The result obtained for each run was the mean of three experiments.

2.7. Optimization of LA Production by Central Composite Design. The central composite design (CCD) with 3 independent variables (nitrogen source, temperature, and carbon source) was used to determine the optimal conditions for the production of LA; indeed, these factors are those that have previously shown a significant effect on lactic acid production. The ranges of the different independent variables used were, respectively, $30-90 \mathrm{ml} / \mathrm{l}$ for the nitrogen source, 25 $40^{\circ} \mathrm{C}$ for the temperature, and $300-800 \mathrm{~g} / \mathrm{l}$ for the carbon source. A total of 20 experimental runs with six replications at the center point (Table 3) were completed, and evaluation of the lactic acid production expressed as response was determined. The result was mean of triplicate.

Data were fitted to a second-degree polynomial model $(Y)$ of the form presented in the following:

$$
\begin{aligned}
Y= & \beta_{0}+\beta_{1} X_{1}+\beta_{2} X_{2}+\beta_{3} X_{3}+\beta_{11} X_{1}^{2}+\beta_{22} X_{2}^{2}+\beta_{33} X_{3}^{2} \\
& +\beta_{12} X_{1} X_{2}+\beta_{13} X_{1} X_{3}+\beta_{23} X_{2} X_{3},
\end{aligned}
$$

where $Y$ represents the response (LA concentration); $\beta_{0}$ is the constant; $\beta_{1}, \beta_{2}$, and $\beta_{3}$ are the linear coefficients; $\beta_{11}$, $\beta_{22}$, and $\beta_{33}$ are square coefficients; $\beta_{12}, \beta_{13}$, and $\beta_{23}$ are the interaction coefficient; and $X_{1}, X_{2}, X_{3}, X_{1}, X_{22}, X_{32}, X_{1}$ $X_{2}, X_{1} X_{3}$, and $X_{2} X_{3}$ are the levels of independent variables. Three experimental replicates were performed under optimized conditions to validate the optimum conditions of LA production. The experimental and predicted concentration of LA were compared, and to verify the validity and robustness of the predictive model, the coefficient of determination $\left(R^{2}\right)$, bias factor $(\mathrm{Bf})$, and absolute average deviation (AAD) were used.

2.8. Statistical Analysis. The Minitab 18 software was used for the experimental design; then the power of the model was assessed by evaluating the coefficient of determination $\left(R^{2}\right)$ obtained from the analysis of variance (ANOVA). Using the same software, the results expressed as a mean \pm standard deviation were analyzed by the analysis of variance (ANOVA) test, followed by comparisons of the means between them by the Fisher test at the 0.05 probability 
TABLE 1: Real levels of variables used in definitive plan.

\begin{tabular}{lcccc}
\hline Variables & Codes & \multicolumn{3}{c}{ Range and levels } \\
& & -1 & 0 & +1 \\
\hline $\mathrm{MgSO}_{4}(\mathrm{~g} / \mathrm{l})$ & $X_{1}$ & 0 & 0.3 & 0.6 \\
$\mathrm{MnSO}_{4}(\mathrm{~g} / \mathrm{l})$ & $X_{2}$ & 0 & 0.025 & 0.05 \\
${\mathrm{Temperature}\left({ }^{\circ} \mathrm{C}\right)}$ & $X_{3}$ & 30 & 37.5 & 45 \\
$\mathrm{FeSO}_{4}(\mathrm{~g} / \mathrm{l})$ & $X_{4}$ & 0 & 0.025 & 0.05 \\
$\mathrm{~K}_{2} \mathrm{HPO}_{4}(\mathrm{~g} / \mathrm{l})$ & $X_{5}$ & 0 & 0.4 & 0.8 \\
$\mathrm{kH}_{2} \mathrm{PO}_{4}(\mathrm{~g} / \mathrm{l})$ & $X_{6}$ & 0 & 0.4 & 0.8 \\
$\mathrm{NS}(\mathrm{ml} / \mathrm{l})$ & $X_{7}$ & 0 & 30 & 60 \\
$\mathrm{CS}(\mathrm{g} / \mathrm{l})$ & $X_{8}$ & 100 & 300 & 500 \\
\hline
\end{tabular}

threshold. Then, Sigma Plot v11.0 (c) systat was used for plotting the response surface plots.

\section{Results}

3.1. Lactic Acid Production. The kinetics of LA production by Lactiplantibacillus plantarum strain $4 \mathrm{O} 8$ and those of the consumption of reducing sugars over time are illustrated in Figure 1. From this figure, it can be seen that LA production varies from one production medium to another; furthermore, there is a progression in LA concentrations over time and a subsequent decrease in reducing sugar concentrations in the different production media. In fact, in most fermentation broth, more than $50 \%$ of the initial quantity of reducing sugars is consumed by the fermenting strain between 0 and 16 hours of fermentation (Figure 1(b)), which results in a lower production of LA between 16 and 48 hours (Figure 1(a)). For this reason, the kinetic parameters (Table 4) were evaluated at $16 \mathrm{~h}$ after the start of fermentation. Carrying out fermentation in batch mode, the LA concentrations after $16 \mathrm{~h}$ of fermentation varied between $7.68 \pm 0.00 \mathrm{~g} / \mathrm{l}$ (fermentation broth without a nitrogen source (WNS)) and $14.64 \pm 0.05 \mathrm{~g} / \mathrm{l}$ (BC). Chicken byproducts were the most nutritious source of nitrogen for the lactic ferment because, in this production medium, the volumetric productivity recorded $(0.92 \pm 0.00 \mathrm{~g} / \mathrm{l} / \mathrm{h})$ was significantly different than the others $(p<0.05)$. Moreover, fish byproducts came in the second position as they allowed the Lactiplantibacillus plantarum strain $4 \mathrm{O} 8$ to achieve a production performance in LA of $0.84 \pm 0.00 \mathrm{~g} / \mathrm{l} / \mathrm{h}$. Thus, it is clear from Table 4 that the best sources of nitrogen are $\mathrm{BC}$ and $\mathrm{BF}$.

3.2. Determination of the Proximate Composition of the Best Nitrogen Sources. Table 5 shows the results obtained in the determination of the proximate composition of $\mathrm{BC}$ and $\mathrm{BF}$. Majority of the parameters determined vary from one nitrogen source to another. Indeed, the highest contents of protein $(83.00 \pm 1.41 \%)$, phosphate $(617.00 \pm 2.83 \mathrm{mg} / 100 \mathrm{~g})$, magnesium $(58.54 \pm 0.65 \mathrm{mg} / 100 \mathrm{~g})$, and sodium $(251.61 \pm 0.56 \mathrm{mg} / 100 \mathrm{~g})$ were present in $\mathrm{BC}$; these values are significantly different from those obtained from $\mathrm{BF}$ $(p<0.05)$. The same applies to the potassium, iron, and zinc contents. However, BF contains the highest amounts of lipids $(8.71 \pm 0.13 \%)$, ash $(6.00 \pm 0.00 \%)$, and manganese
$(0.05 \pm 0.00 \%)$; in fact, there is a significant difference between these contents and those obtained from the BC $(p<0.05)$. Moreover, no significant difference was observed between the dry matter and Ca contents of the two samples $(p>0.05)$.

Given the LA production obtained in the production medium containing $\mathrm{BC}$ as nitrogen source, and taking into account its protein content, it is clear that $\mathrm{BC}$ is the most promising nitrogen source.

3.3. Factors Influencing LA Production. Table 3 groups the experimental values of the responses measured during the experiments proposed by the experimental design according to the factors studied. It shows that the LA concentrations varied between $0.25 \pm 0.02 \mathrm{~g} / \mathrm{l}$ and $15.41 \pm 0.05 \mathrm{~g} / \mathrm{l}$; this table also shows that the lowest LA concentrations were obtained when the incubation temperature was $45^{\circ} \mathrm{C}$.

(1) ANOVA: Contribution of Factors. The effects of factors on responses studied are illustrated by the Pareto diagram (Figure 2); it shows that among all the variables studied and at the chosen confidence level $(p<0.05)$, the linear and quadratic effects of temperature, nitrogen source, carbon source, $\mathrm{FeSO}_{4}$, and $\mathrm{MgSO}_{4}$ appear in decreasing order as very influential factors on LA production. Also, two interactions also showed a pronounced influence on the response studied; this was the interactions between temperature and the nitrogen source and the interaction between $\mathrm{FeSO}_{4}$ and the nitrogen source.

Table 6 presents the contributions of the most significant factors influencing $(p<0.05)$ LA production. It appears that the temperature is the factor having a major impact on the evaluated response $\left(\mathrm{CF}=58.59\left(X_{3}\right)+18.37\left(X_{3} X_{3}\right)=76.96\right.$ ) followed by the nitrogen source $\left(\mathrm{CF}=8.20\left(X_{7}\right)\right)$ and carbon source $\left(\mathrm{CF}=2.96\left(X_{8}\right)\right)$. The mathematical model (second-degree polynomial model) of relationship for LA with the most significant factors influencing LA production is given by the equation below. From this equation, it can be seen that the linear effects of temperature, nitrogen source, carbon source, $\mathrm{FeSO}_{4}$, and $\mathrm{MgSO}_{4}$ positively affect the evaluated response. In addition, the quadratic effect of temperature, and also the interactions between temperature and the nitrogen source and the one between $\mathrm{FeSO}_{4}$ and the nitrogen source negatively, affects the lactic acid production.

$$
\begin{aligned}
Y= & -110.3+1.693 \mathrm{Mg}+6.560 \text { Temperature }+56.0 \text { FESO } 4 \\
& +0.3470 \text { Nitrogen source } \\
& +0.00496 \text { Carbon source }-0.09251 \text { Temperature } \\
& \times \text { Temperature } \\
& -0.007033 \text { Temperature } \times \text { Nitrogen source } \\
& -1.126 \mathrm{FESO} 4 \times \text { Nitrogen source }
\end{aligned}
$$

3.4. Optimization of LA Production. Here, temperature, carbon source, and nitrogen source were used for the optimization. Indeed, among the most significant factors influencing LA production, $\mathrm{FeSO}_{4}$ and $\mathrm{MgSO}_{4}$ have the lowest 
TABLe 2: Definitive plan design (real and coded values) with the respective results.

\begin{tabular}{|c|c|c|c|c|c|c|c|c|c|c|}
\hline \multirow{2}{*}{ No. } & \multicolumn{8}{|c|}{ Independent variables } & \multicolumn{2}{|c|}{ Lactic acid $(\mathrm{g} / \mathrm{l})$} \\
\hline & $X_{1}$ & $X_{2}$ & $X_{3}$ & $X_{4}$ & $X_{5}$ & $X_{6}$ & $X_{7}$ & $X_{8}$ & Experimental values & Predicted values \\
\hline 1 & $0.6(1)$ & $0.025(0)$ & $45(1)$ & $0(-1)$ & $0.8(1)$ & $0(-1)$ & $0(-1)$ & $500(1)$ & $1.11 \pm 0.01$ & 1.11 \\
\hline 2 & $0(-1)$ & $0(-1)$ & $45(1)$ & $0(-1)$ & $0(-1)$ & $0.8(1)$ & $30(0)$ & $500(1)$ & $1.11 \pm 0.00$ & 1.05 \\
\hline 3 & $0.6(1)$ & $0(-1)$ & $30(-1)$ & $0.05(1)$ & $0.4(0)$ & $0.8(1)$ & $0(-1)$ & $500(1)$ & $9.41 \pm 0.00$ & 9.59 \\
\hline 4 & $0.6(1)$ & $0(-1)$ & $45(1)$ & $0.05(1)$ & $0(-1)$ & $0(-1)$ & $60(0)$ & $300(0)$ & $1.13 \pm 0.00$ & 1.39 \\
\hline 5 & $0.3(0)$ & $0.025(0)$ & $37.5(0)$ & $0.025(0)$ & $0.4(0)$ & $0.4(0)$ & $30(0)$ & $300(0)$ & $11.79 \pm 0.00$ & 10.71 \\
\hline 6 & $0(-1)$ & $0(-1)$ & $45(1)$ & $0.05(1)$ & $0.8(1)$ & $0.4(0)$ & $0(-1)$ & $100(-1)$ & $0.90 \pm 0.05$ & 0.95 \\
\hline 7 & $0(-1)$ & $0.05(1)$ & $30(-1)$ & $0(-1)$ & $0.8(1)$ & $0.8(1)$ & $0(-1)$ & $300(0)$ & $5.49 \pm 0.01$ & 4.79 \\
\hline 8 & $0(-1)$ & $0(-1)$ & $30(-1)$ & $0.025(0)$ & $0.8(1)$ & $0(-1)$ & $60(1)$ & $500(1)$ & $12.94 \pm 0.02$ & 13.65 \\
\hline 9 & $0.6(1)$ & $0(-1)$ & $37.5(0)$ & $0(-1)$ & $0.8(1)$ & $0.8(1)$ & $60(1)$ & $100(-1)$ & $11.48 \pm 0.03$ & 12.19 \\
\hline 10 & $0.6(1)$ & $0.05(1)$ & $30(-1)$ & $0(-1)$ & $0(-1)$ & $0.4(0)$ & $60(1)$ & $500(1)$ & $15.41 \pm 0.05$ & 14.96 \\
\hline 11 & $0(-1)$ & $0.05(1)$ & $45(1)$ & $0(-1)$ & $0.4(0)$ & $0(-1)$ & $60(1)$ & $100(-1)$ & $0.35 \pm 0.02$ & 0.025 \\
\hline 12 & $0.6(1)$ & $0.05(1)$ & $45(1)$ & $0.025(0)$ & $0(-1)$ & $0.8(1)$ & $0(-1)$ & $100(-1)$ & $0.47 \pm 0.02$ & 0.54 \\
\hline 13 & $0.3(0)$ & $0.05(1)$ & $45(1)$ & 0.05 (1) & $0.8(1)$ & $0.8(1)$ & $60(1)$ & $500(1)$ & $1.88 \pm 0.03$ & 1.88 \\
\hline 14 & $0.3(0)$ & $0(-1)$ & $30(-1)$ & $0(-1)$ & $0(-1)$ & $0(-1)$ & $0(-1)$ & $100(-1)$ & $3.35 \pm 0.03$ & 4.31 \\
\hline 15 & $0(-1)$ & $0.025(0)$ & $30(-1)$ & $0.05(1)$ & $0(-1)$ & $0.8(1)$ & $60(1)$ & $100(-1)$ & $11.36 \pm 0.00$ & 11.37 \\
\hline 16 & $0.6(1)$ & $0.05(1)$ & $30(-1)$ & $0.05(1)$ & $0.8(1)$ & $0(-1)$ & $30(0)$ & $100(-1)$ & $10.73 \pm 0.02$ & 9.99 \\
\hline 17 & $0(-1)$ & $0.05(1)$ & $37.5(0)$ & $0.05(1)$ & $0(-1)$ & $0(-1)$ & $0(-1)$ & $500(1)$ & $10.58 \pm 0.02$ & 10.94 \\
\hline
\end{tabular}

$(-1),(0)$, and (1) are coded levels.

TABle 3: Experimental design for the optimization process of lactic acid production.

\begin{tabular}{|c|c|c|c|c|c|c|c|c|}
\hline \multirow[b]{2}{*}{ Run } & \multicolumn{3}{|c|}{ Coded levels } & \multicolumn{3}{|c|}{ Real levels } & \multicolumn{2}{|c|}{ Lactic acid $(\mathrm{g} / \mathrm{l})$} \\
\hline & $X_{1}$ & $X_{2}$ & $X_{3}$ & $\begin{array}{c}\text { Nitrogen source }(\mathrm{ml} / \mathrm{l}) \\
\left(X_{1}\right)\end{array}$ & $\begin{array}{c}\text { Temperature }\left({ }^{\circ} \mathrm{C}\right) \\
\left(X_{2}\right)\end{array}$ & $\begin{array}{c}\text { Carbone source }(\mathrm{g} / \mathrm{l}) \\
\left(\mathrm{X}_{3}\right)\end{array}$ & $\begin{array}{l}\text { Experimental } \\
\text { values }\end{array}$ & $\begin{array}{l}\text { Predicted } \\
\text { values }\end{array}$ \\
\hline 1 & 1 & -1 & -1 & 90 & 25 & 300 & $17.21 \pm 0.00$ & 17.11 \\
\hline 2 & -1 & -1 & -1 & 30 & 25 & 300 & $16.75 \pm 0.01$ & 17.77 \\
\hline 3 & 0 & 0 & 0 & 60 & 32.5 & 550 & $17.60 \pm 0.01$ & 17.64 \\
\hline 4 & 1 & -1 & 1 & 90 & 25 & 800 & $15.52 \pm 0.01$ & 16.32 \\
\hline 5 & 0 & 0 & 0 & 60 & 32.5 & 550 & $17.59 \pm 0.01$ & 17.64 \\
\hline 6 & -1 & 1 & -1 & 30 & 40 & 300 & $14.65 \pm 0.02$ & 13.52 \\
\hline 7 & -1 & -1 & 1 & 30 & 25 & 800 & $17.22 \pm 0.02$ & 17.53 \\
\hline 8 & 1 & 1 & 1 & 90 & 40 & 800 & $17.27 \pm 0.01$ & 15.93 \\
\hline 9 & 0 & 0 & 0 & 60 & 32.5 & 550 & $16.95 \pm 0.02$ & 17.64 \\
\hline 10 & 0 & 0 & 0 & 60 & 32.5 & 550 & $17.10 \pm 0.00$ & 17.64 \\
\hline 11 & -1 & 1 & 1 & 30 & 40 & 800 & $15.55 \pm 0.02$ & 15.33 \\
\hline 12 & 1 & 1 & -1 & 90 & 40 & 300 & $15.30 \pm 0.03$ & 14.66 \\
\hline 13 & 0 & 0 & -1.633 & 60 & 32.5 & 141.75 & $17.55 \pm 0.00$ & 17.92 \\
\hline 14 & 0 & 0 & 0 & 60 & 32.5 & 550 & $17.00 \pm 0.00$ & 16.22 \\
\hline 15 & 0 & 0 & 0 & 60 & 32.5 & 550 & $16.90 \pm 0.00$ & 16.22 \\
\hline 16 & 0 & -1.633 & 0 & 60 & 20.25 & 550 & $11.43 \pm 0.03$ & 10.03 \\
\hline 17 & 0 & 1.633 & 0 & 60 & 44.75 & 550 & $4.36 \pm 0.02$ & 6.24 \\
\hline 18 & 1.633 & 0 & 0 & 109 & 32.5 & 550 & $17.22 \pm 0.02$ & 17.85 \\
\hline 19 & 0 & 0 & 1.633 & 60 & 32.5 & 958.25 & $18.64 \pm 0.01$ & 18.76 \\
\hline 20 & -1.633 & 0 & 0 & 11.01 & 32.5 & 550 & $18.04 \pm 0.01$ & 17.89 \\
\hline
\end{tabular}

$X_{1}$ : nitrogen source; $X_{2}$ : temperature; $X_{3}$ : carbon source.

contributions on the evaluated response $(0.93 \%$ and $0.77 \%$, respectively). Furthermore, these factors have an insignificant contribution on the desirability of our model, which was 1. Moreover, the peak of the LA production was reached when the $\mathrm{FeSO}_{4}$ concentration was $0.00 \mathrm{~g} / \mathrm{l}$, and the curve translating the LA production for the $\mathrm{MgSO}_{4}$ interval 


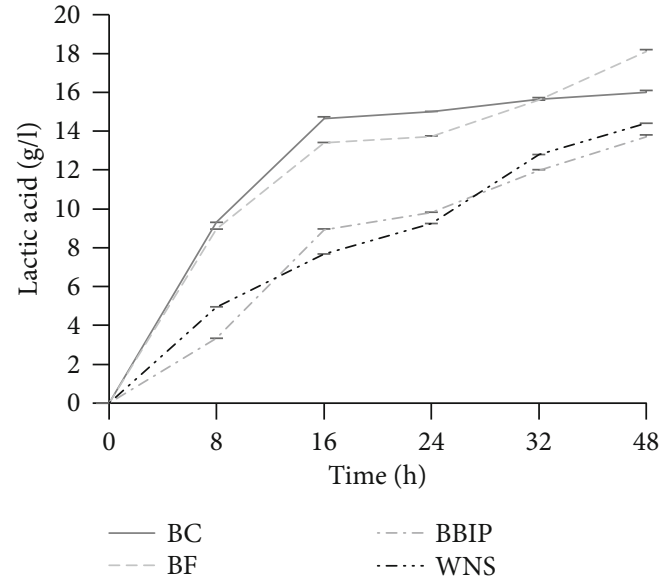

(a)

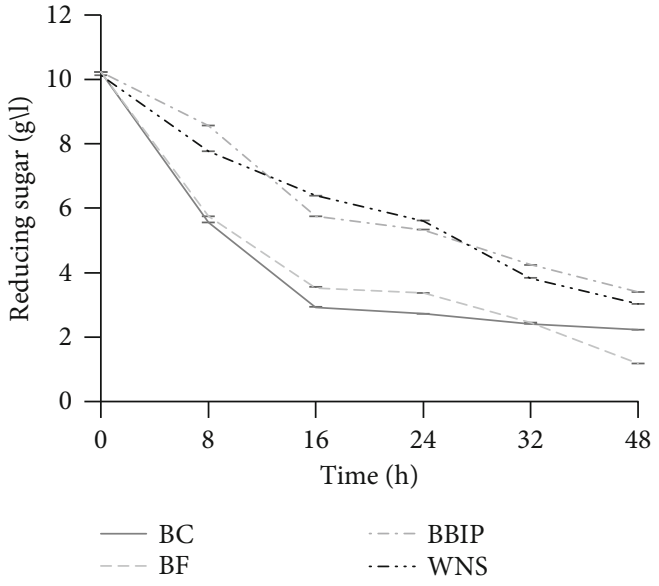

(b)

FIGURE 1: Kinetics of LA production (a) and reducing sugars consumption (b) in different production medium. BC: production medium containing by-products from chicken as nitrogen source; BIPB: production medium containing by-products of the beer production industry as nitrogen source; WNS: production medium without a nitrogen source; BF: production medium containing by-products from fish as nitrogen source.

TABLE 4: Lactic acid, volumetric productivity, and lactic acid yield after $16 \mathrm{~h}$ of fermentation.

\begin{tabular}{lccc}
\hline $\begin{array}{l}\text { Nitrogen } \\
\text { sources }\end{array}$ & $\begin{array}{c}\text { Lactic acid } \\
\text { concentration } \\
(\mathrm{g} / \mathrm{l})\end{array}$ & $\begin{array}{c}\text { Volumetric } \\
\text { productivity } \\
(\mathrm{g} / \mathrm{lh})\end{array}$ & $\begin{array}{c}\text { Lactic acid yield } \\
(\mathrm{mg} / \mathrm{g})\end{array}$ \\
\hline BC & $14.64 \pm 0.05^{\mathrm{a}}$ & $0.92 \pm 0.00^{\mathrm{a}}$ & $29.80 \pm 0.14^{\mathrm{a}}$ \\
BF & $13.4 \pm 0.02^{\mathrm{b}}$ & $0.84 \pm 0.00^{\mathrm{b}}$ & $26.91 \pm 0.13^{\mathrm{b}}$ \\
BBIP & $8.23 \pm 0.04^{\mathrm{c}}$ & $0.56 \pm 0.00^{\mathrm{c}}$ & $17.80 \pm 0.00^{\mathrm{c}}$ \\
WNS & $7.68 \pm 0.00^{\mathrm{d}}$ & $0.48 \pm 0.00^{\mathrm{d}}$ & $15.63 \pm 0.00^{\mathrm{d}}$ \\
\hline
\end{tabular}

$\overline{a, b, c, d}$ Values with different letters on the same column differ significantly each other $(p<0.05)$.

TABle 5: Proximate composition of $\mathrm{BC}$ and $\mathrm{BF}$.

\begin{tabular}{lcc}
\hline Parameter & BC & BF \\
\hline Dry matter $(\% \mathrm{DM})$ & $91.71 \pm 3.32^{\mathrm{a}}$ & $92.78 \pm 2.32^{\mathrm{a}}$ \\
Fat $(\% \mathrm{DM})$ & $1.41 \pm 0.11^{\mathrm{b}}$ & $8.71 \pm 0.13^{\mathrm{a}}$ \\
Protein $(\% \mathrm{DM})$ & $83.00 \pm 1.41^{\mathrm{a}}$ & $74.00 \pm 1.41^{\mathrm{b}}$ \\
Ash $(\% \mathrm{DM})$ & $4.00 \pm 0.00^{\mathrm{b}}$ & $6.00 \pm 0.00^{\mathrm{a}}$ \\
P (mg/100 g) & $617.00 \pm 2.83^{\mathrm{a}}$ & $601.50 \pm 2.12^{\mathrm{b}}$ \\
$\mathrm{Ca}(\mathrm{mg} / 100 \mathrm{~g})$ & $743.50 \pm 0.71^{\mathrm{a}}$ & $741.00 \pm 1.41^{\mathrm{a}}$ \\
$\mathrm{Mn}(\mathrm{mg} / 100 \mathrm{~g})$ & $0.00 \pm 0.00^{\mathrm{b}}$ & $0.05 \pm 0.00^{\mathrm{a}}$ \\
$\mathrm{Mg}(\mathrm{mg} / 100 \mathrm{~g})$ & $58.54 \pm 0.65^{\mathrm{a}}$ & $55.83 \pm 0.240^{\mathrm{b}}$ \\
$\mathrm{Na}(\mathrm{mg} / 100 \mathrm{~g})$ & $251.61 \pm 0.56^{\mathrm{b}}$ & $302.66 \pm 0.484^{\mathrm{a}}$ \\
$\mathrm{K}(\mathrm{mg} / 100 \mathrm{~g})$ & $510.00 \pm 1.41^{\mathrm{a}}$ & $503.00 \pm 1.41^{\mathrm{b}}$ \\
Fe (mg/100 g) & $57.42 \pm 0.12^{\mathrm{a}}$ & $49.62 \pm 0.23^{\mathrm{b}}$ \\
$\mathrm{Zn}(\mathrm{mg} / 100 \mathrm{~g})$ & $1.5 \pm 0.014^{\mathrm{a}}$ & $0.87 \pm 0.07^{\mathrm{b}}$ \\
\hline
\end{tabular}

${ }^{\mathrm{a}, \mathrm{b}}$ Values with different letters on the same column differ significantly each other $(p<0.05)$. BC: by-product from chicken; BF: by-product from fish. considered was almost linear which expresses the absence of significant difference in LA production in this interval (Figure 3); it is for these reasons that these two factors were not taken into account for the optimization.

The LA concentrations obtained after the 20 experimental trials are summarized in Table 3. It appears that the LA concentrations ranged from $4.36 \pm 0.02 \mathrm{~g} / \mathrm{l}$ to $18.64 \pm 0.01 \mathrm{~g}$ /l. Furthermore, this table also shows that the lowest LA concentration is obtained when the incubation temperature is the highest $\left(44.75^{\circ} \mathrm{C}\right)$.

(1) Contribution of independent variables and validation of the model. The contribution of the independent variables and model validation are grouped in Table 7 . It can be seen that the production of LA is influenced by linear and quadratic temperature effects, but also by the quadratic effects of the carbon source. Indeed, the temperature is the factor having the most effect on the production of LA because it has a major impact on the evaluated response $\left(\mathrm{CF}=9.54\left(X_{2}\right)+67.17\left(X_{2} X_{2}\right)=76.71\right)$. This table also shows that for the model, $R^{2}, \mathrm{AAD}$, and Bf were 92.98, 0.00 , and 0.90 , respectively. The mathematical equation resulting from our design of experiment optimization which can predict the variation of LA production according to the nitrogen source $\left(X_{1}\right)$, temperature $\left(X_{2}\right)$, and carbon source $\left(X_{3}\right)$ is mentioned in the following:

$$
\begin{aligned}
Y= & -20.96-0.1385 X_{1}+3.076 X_{2}-0.0207 X_{3} \\
& +0.000690 X_{1} \times X_{1}-0.05386 X_{2} \times X_{2} \\
& +0.000013 X_{3} \times X_{3}+0.00201 X_{1} \times X_{2} \\
& -0.000018 X_{1} \times X_{3}+0.000273 X_{2} \times X_{3} .
\end{aligned}
$$

(2) Response Surface Plot of LA Production. The interaction between temperature and carbon source was the one that showed a major impact on the evaluated response with a 


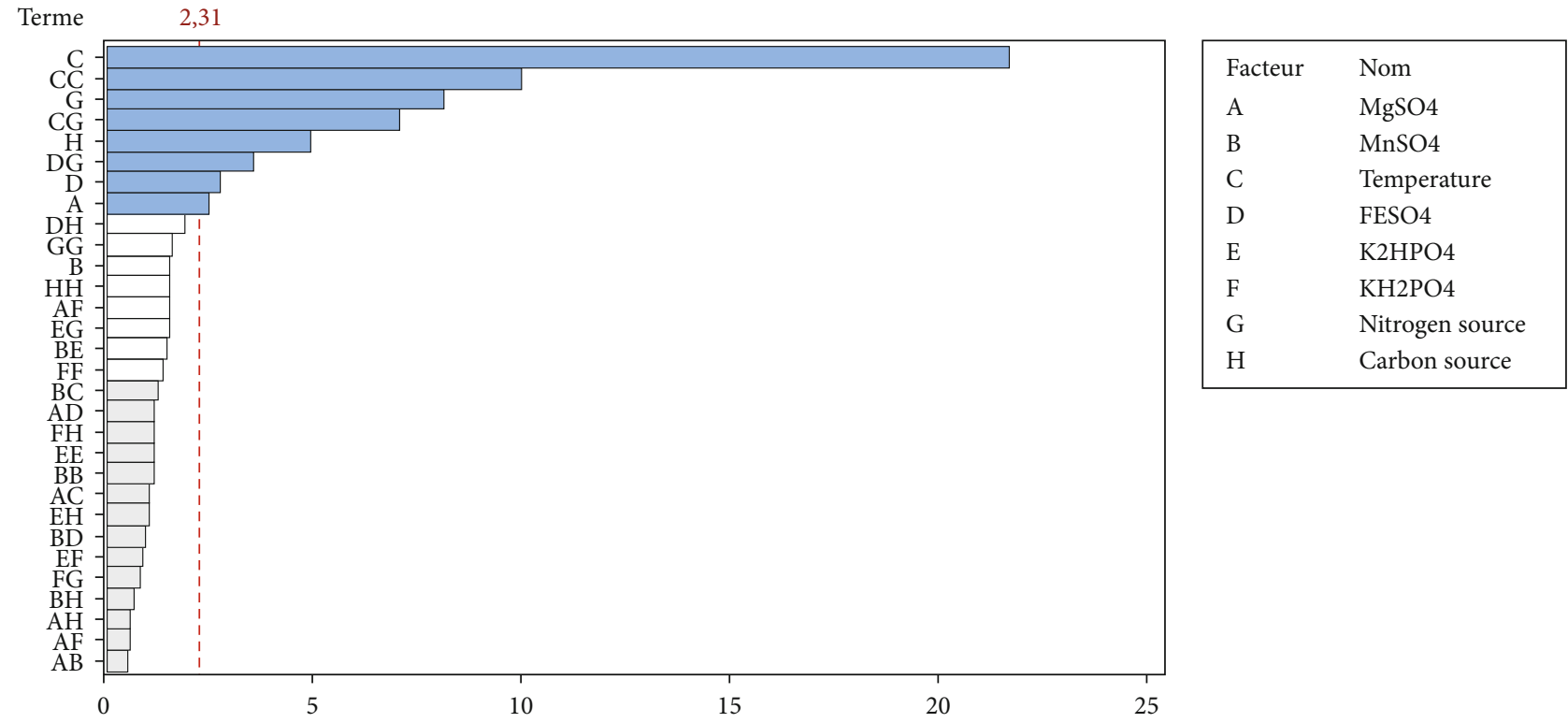

FIGURE 2: Pareto chart of the effects of variables on LA production in fermentation broth. The grey bars represent terms not included in the model.

TABLE 6: Analysis of variance ( $p$ values, contribution of factors $(\mathrm{CF})$, and coefficient of factors (Coeff).

\begin{tabular}{lccc}
\hline & Coeff & $p$ & CF\% \\
\hline$X_{1}$ & 0.508 & 0.0370 & 0.77 \\
$X_{3}$ & -4.417 & 0.0001 & 58.59 \\
$X_{4}$ & 0.556 & 0.0250 & 0.93 \\
$X_{7}$ & 1.653 & 0.0001 & 8.20 \\
$X_{8}$ & 0.993 & 0.0010 & 2.96 \\
$X_{3} X_{3}$ & -5.204 & 0.0001 & 18.37 \\
$X_{3} X_{7}$ & -1.583 & 0.0001 & 7.64 \\
$X_{4} X_{7}$ & -0.845 & 0.0080 & 1.54 \\
\hline$X_{1}: X_{3}: X_{3}:$ &
\end{tabular}

$X_{1}: \mathrm{MgSO}_{4} ; X_{3}$ : temperature; $\mathrm{X}_{4}: \mathrm{FeSO}_{4} ; \mathrm{X}_{7}$ : nitrogen source; $\mathrm{X}_{8}$ : carbon source.

contribution of $1.11 \%$ (Table 7 ); it is for this reason that only the response surface plot showing the interaction between these two factors on LA production (Figure 4) was solicited. This figure shows that the areas of maximum activity are marked by the orange colour and correspond to LA concentrations between 20 and $22 \mathrm{~g} / \mathrm{l}$. The areas of minimum activity are represented by the blue colouring.

(3) Contour Plot of LA Production. Figure 5 is a contour plot that visualises the areas of optimal variation of LA production as a function of temperature and carbon source content. The hatched areas represent the location of the maxima of this response, while the nonhatched areas represent the lowest values. The areas of interest are those where the LA concentration is higher than $18 \mathrm{~g} / \mathrm{l}$. These zones of interest define the experimental domain in which the application of the relevant conditions (temperature and carbon source content) will allow maximum LA production.
(4) Optimum Conditions and Validation of the Optimal Conditions. To confirm that there is coherence between theory and experiment optimum conditions, additional manipulations were carried out in the laboratory according to the optimal conditions predicted by the mathematical model (Table 8). The obtained experimental optimal values $(20.93 \pm 0.12 \mathrm{~g} / \mathrm{l})$ were compared to the predicted values $(20.75 \pm 00 \mathrm{~g} / \mathrm{l})$ to validate the optimal conditions defined by the model, and it was found that no significant difference was observed between these two values $(p<0.05)$.

3.5. LA Production Performance of Lactiplantibacillus Plantarum Strain 4O8. Table 9 summarises the LA production performance of Lactiplantibacillus plantarum strain 408 in the production medium that was not supplemented with nitrogen source, but also in the fermentation broth containing BC as nitrogen source with the nonoptimized conditions and under optimization conditions. From this table, it can be seen that LA concentration obtained in the production medium under optimizing conditions $(20.93 \pm 0.12 \mathrm{~g} / \mathrm{l}$ ) is significantly different than the others $(p<0.05)$. This table also shows that optimizing the production of LA using $\mathrm{BC}$ as a nitrogen source can multiply the performance of the lactic acid bacteria by a factor of 2.73 .

\section{Discussion}

In our study, Lactiplantibacillus plantarum strain $4 \mathrm{O} 8$ showed its ability to produce significantly small amounts of LA after $16 \mathrm{~h}$ of fermentation in production media that were not supplemented with a nitrogen source. This phenomenon is explained by the low protein content of the pineapple byproducts used as a carbon source for the preparation of the fermentation broth [8]. Indeed, to ensure good growth of the lactic ferment and consequent production of LA, the 


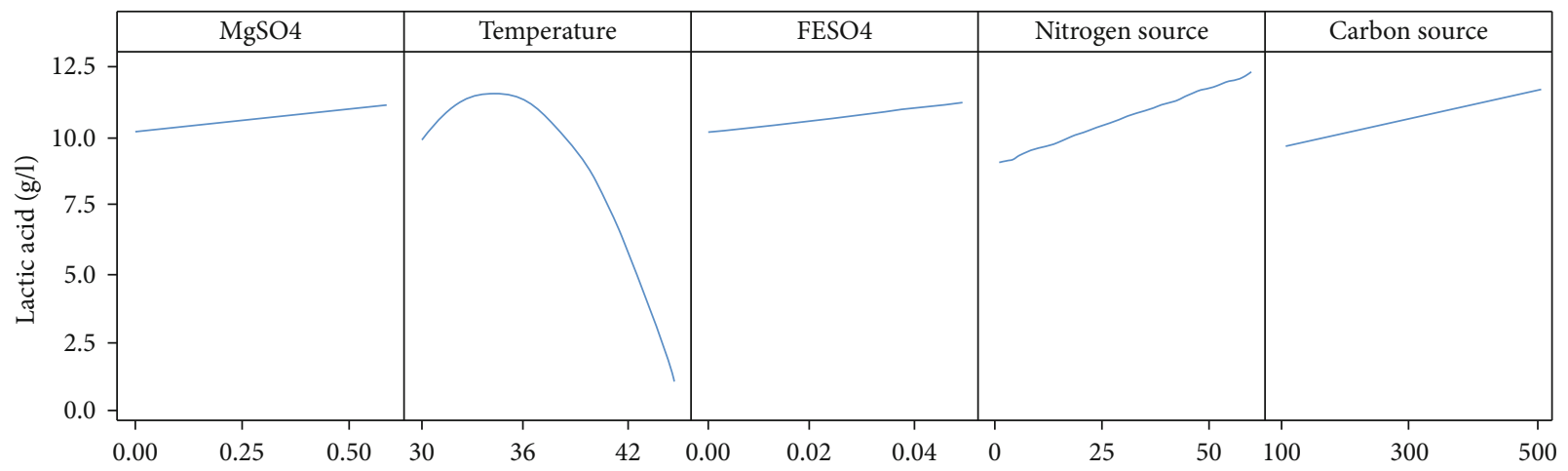

FIGURE 3: Effects of factors on LA production.

TABLE 7: $p$ values, contribution of factors (CF) coefficient of determination $\left(R^{2}\right)$, absolute average deviation (AAD), and bias factor (Bf) for optimized production of LA following CCD design.

\begin{tabular}{lcc}
\hline & $p$ & CF\% \\
\hline$X_{1}$ & 0.9630 & 0.00 \\
$X_{2}$ & $0.0070^{*}$ & 9.54 \\
$X_{3}$ & 0.4580 & 0.47 \\
$X_{1} X_{1}$ & 0.0960 & 4.20 \\
$X_{2} X_{2}$ & $0.0001^{*}$ & 67.17 \\
$X_{3} X_{3}$ & $0.0410^{*}$ & 4.43 \\
$X_{1} X_{2}$ & 0.3200 & 0.87 \\
$X_{1} X_{3}$ & 0.7580 & 0.08 \\
$X_{2} X_{3}$ & 0.2630 & 1.11 \\
Model validation & & \\
$R^{2}$ & & 92.98 \\
AAD & & 0.00 \\
Bf & & 0.9 \\
\hline
\end{tabular}

*Independent variable that significantly $(p<0.05)$ affects the response. $X_{1}$ : nitrogen source; $X_{2}$ : temperature; $X_{3}$ : carbon source.

production medium must contain a sufficient quantity of protein to meet the nitrogen requirements of the fermenting strain [26]. Moreover, this LA production was improved when the different production media were supplemented with $\mathrm{BC}, \mathrm{BF}$, and BBIP; these by-products would therefore be potential sources of amino acids and peptides that served as a nitrogen source for the lactic ferment. Similar observations were reported by Kaktcham et al. [9] who in their work used fish by-products as a nitrogen source in a liquid medium formulated to optimize the production of bacteriocin by the Lactococcus lactis subsp. lactis 2MT strain. The low concentrations recorded in the various production media supplemented with BC, BF, and BBIP after $16 \mathrm{~h}$ of fermentation were due to the drop of more than $50 \%$ in the initial reducing sugar concentration, but also by the acidity of the medium due to the accumulation of LA [10], since the trials was performed in batch mode. The highest concentration of LA $(14.64 \pm 0.05 \mathrm{~g} / \mathrm{l})$ was obtained in the production medium in which $\mathrm{BC}$ was the nitrogen source; this can be explained simply by the protein composition of $\mathrm{BC}$, which was the highest. These results are in agreement with those of Coelho et al. [4] who, in the context of their work, showed that LA production depended on the protein concentration in the production medium. The aforementioned LA concentration $(14.64 \pm 0.05 \mathrm{~g} / \mathrm{l})$ is significantly higher than that recorded (4.68 g/l) by Umesh and Preethi [13] who not only used pineapple by-products but also supplemented their production medium with MRS. The fact that fish byproducts were the second most nutritious nitrogen source for Lactiplantibacillus plantarum strain $4 \mathrm{O} 8$ can be explained by its polyunsaturated fatty acid composition. Indeed Mouokeu et al. [27] showed in their work that omega-3 and omega-6 fatty acids (eicosapentaenoic and docosahexaenoic acid) had antimicrobial activity. Thus, these fatty acids would have been an obstacle to the optimal growth of the lactic ferment, resulting in a lower LA production.

$\mathrm{BC}$ and $\mathrm{BF}$ were the best nitrogen sources obtained in our investigation. The origin, genus, species, diet, geographical and climatic conditions, and the different parts of the animal constituting the by-products would be the plausible explanation for the differences between the values obtained when determining the proximate composition of these byproducts [28-30].

Our study is also aimed at determining the factors that can influence the production of LA. Among the 8 factors considered, carbon source, nitrogen source (BC), temperature, $\mathrm{MgSO}_{4}$, and $\mathrm{FeSO}_{4}$ showed a major impact on the growth of Lactiplantibacillus plantarum strain $4 \mathrm{O} 8$ and consequently on its production of LA; similar data have been reported by several authors $[4,31,32] . \mathrm{MnSO}_{4}, \mathrm{KH}_{2} \mathrm{PO}_{4}$, and $\mathrm{KHPO}_{4}$ were the factors that in our study did not show a significant effect on the response studied $(p>0.05)$; these observations are contrary to those reported by Boudjelal and Nancib [32] and could be explained by the fact that the nutritional requirements of lactic acid bacteria in mineral salts vary from one strain of lactic acid bacteria to another to [33].

In the present study, temperature, carbon source, and nitrogen source were the factors used for optimization. Indeed, among the most significant factors influencing LA production, $\mathrm{FeSO}_{4}$ and $\mathrm{MgSO}_{4}$ had the lowest contributions on the studied response. Furthermore, these factors had an insignificant contribution to the desirability of our model. 

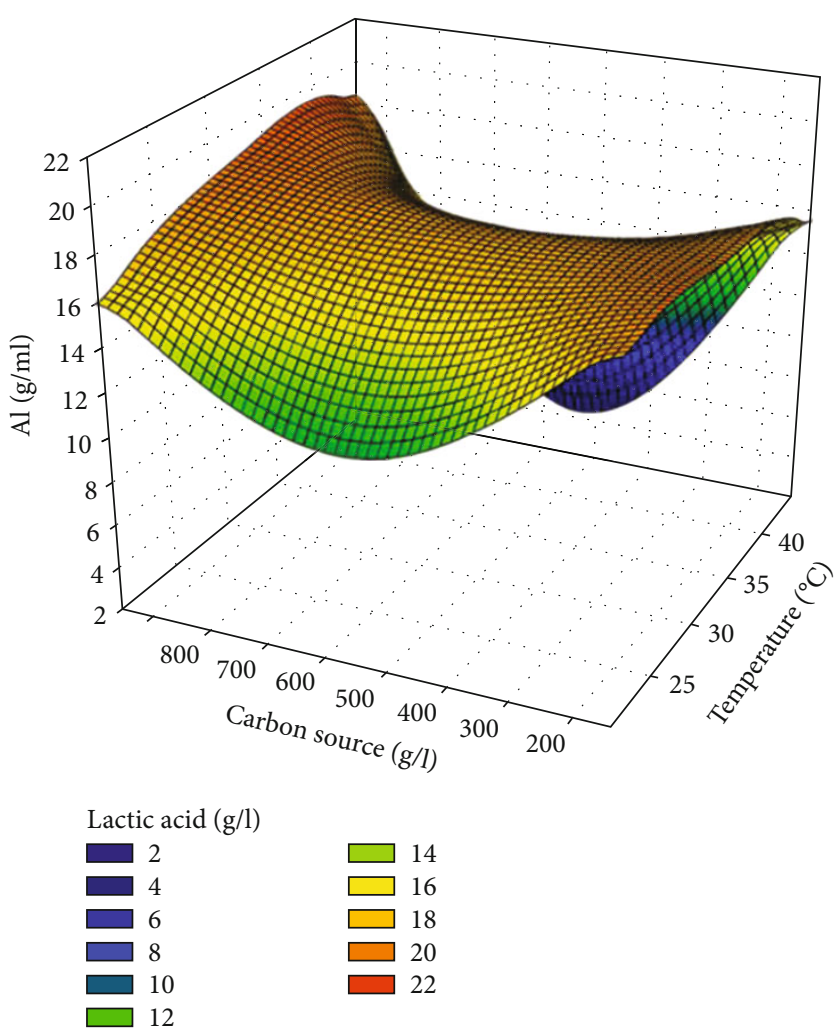

FIgURE 4: Response surface plot showing the interaction between carbon source and temperature on LA production.
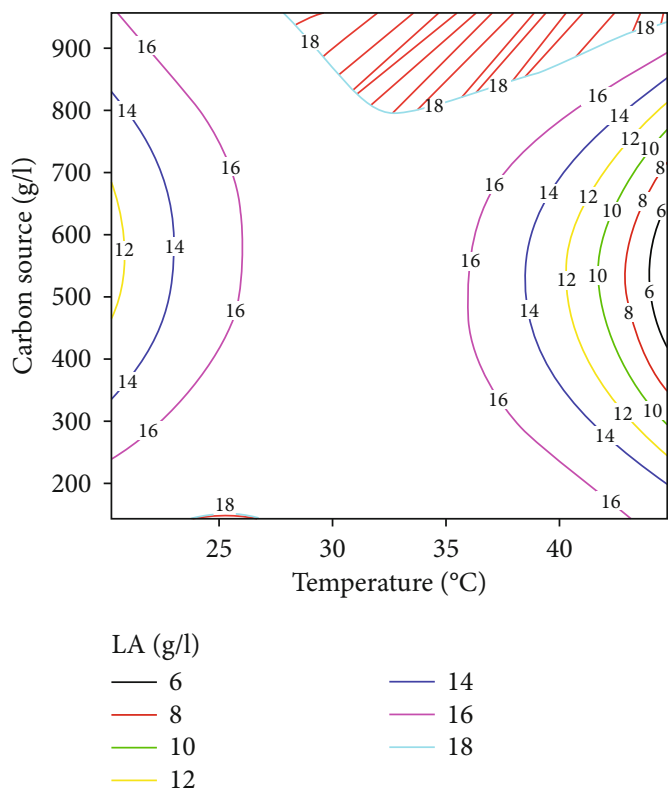

Figure 5: Contour plot showing the effect of carbon source and temperature on lactic acid production.

In addition, the peak of the LA production was reached when the $\mathrm{FeSO}_{4}$ concentration was $0.00 \mathrm{~g} / \mathrm{l}$, and the curve translating the LA production for the $\mathrm{MgSO}_{4}$ interval considered was almost linear which expresses the absence of significant difference in LA production in this interval. Thus, it
TABle 8: Predicted and experimental lactic acid production using optimal culture conditions.

\begin{tabular}{lc}
\hline Parameters & Values \\
\hline Optimum conditions & \\
Nitrogen source $(\mathrm{ml} / \mathrm{l})$ & 108.99 \\
Temperature $\left({ }^{\circ} \mathrm{C}\right)$ & 30.89 \\
Carbon source $(\mathrm{g} / \mathrm{l})$ & 141.75 \\
Validation of optimum conditions & \\
Optimal predicted concentration of LA $(\mathrm{g} / \mathrm{l})$ & $20.75 \pm 00^{\mathrm{a}}$ \\
Optimal experimental concentration of LA $(\mathrm{g} / \mathrm{l})$ & $20.93 \pm 0.12^{\mathrm{a}}$ \\
Desirability & 1 \\
\hline
\end{tabular}

${ }^{a}$ Values with the same letter on the same column are not significantly different each other $(p<0.05)$.

is for these reasons that these two factors were not taken into account for the optimization. Similar data were reported by Myers et al. [34] whose work focused on response surface methodology: process and product optimization using designed experiment.

Within the framework of the optimization of the LA production, the values of the different mathematical tools for model validation obtained were $92.98,0.00$, and 0.9 for $R^{2}, \mathrm{AAD}$, and $\mathrm{Bf}$, respectively. So, the $R^{2}$ value indicates that $92.98 \%$ of the results obtained were attributed to the independent variables and only $7.02 \%$ of the variation cannot be explained by the model. Indeed, these values are in agreement with those reported in the literature $\left(R^{2}>0.75\right.$; AAD $=0 ; 0.75<\mathrm{Bf}<1.25$ for $\mathrm{BF}$ ) [35], and therefore, our model accounts well for the variation in the response studied and can predict the evolution of our phenomenon.

The application of optimal conditions allowed us to obtain an experimental LA production of $20.93 \pm 0.12 \mathrm{~g} / \mathrm{l}$ $(1.308 \pm 0.01 \mathrm{~g} / \mathrm{lh})$ : a value not significantly different from the optimal value predicted by the model which was 20.75 $\pm 0.00(p>0.05)$. It therefore emerges that to obtain maximum LA production after 16 hours of fermentation, a temperature of $30.89^{\circ} \mathrm{C}$ and a carbon and nitrogen source concentration of $141.75 \mathrm{~g} / \mathrm{l}$ and $108.99 \mathrm{ml} / \mathrm{l}$, respectively, are required. The optimal temperature mentioned above is in agreement with the data reported by Abbasiliasi et al. [31]; in fact, the Lactiplantibacillus plantarum strain $4 \mathrm{O} 8$ used as a fermentation agent in our study is a mesophilic lactic acid bacteria whose optimal growth temperature is between 30 and $40^{\circ} \mathrm{C}$. The VP aforementioned $(1.308 \pm 0.01 \mathrm{~g} / \mathrm{lh})$ is higher than the one obtained $(0.331 \mathrm{~g} / \mathrm{l} \mathrm{h})$ by Mufidah and Wakayama [12] who, in the course of their work, used a lactic acid bacteria and a fungi strains for LA production from banana peel. Similarly, the most important LA productivity $(1.12 \mathrm{~g} / \mathrm{l} / \mathrm{h})$ reported by Costa et al. [36] in their study on lactic acid production from agri-food residues as carbon sources is lower than that highlighted in the present work. The use of carob, banana, and sugarcane lignocellulose biomass for LA production was the subject of a study conducted by Azaizeh et al. [37]; it revealed that LA production from these carbohydrate substrates with yeast extract were $54.8 \mathrm{~g} / \mathrm{l}, 26.6 \mathrm{~g} / \mathrm{l}$, and $46.5 \mathrm{~g} / \mathrm{l}$, 
TABLE 9: Lactic acid production of Lactiplantibacillus plantarum strain $4 \mathrm{O} 8$ using $\mathrm{BC}$ and yeast extract.

\begin{tabular}{lccc}
\hline $\begin{array}{l}\text { Production } \\
\text { medium }\end{array}$ & PM-WNS & $\begin{array}{c}\text { PM-BC without } \\
\text { optimization }\end{array}$ & $\begin{array}{c}\text { PM-BC under } \\
\text { optimization } \\
\text { conditions }\end{array}$ \\
\hline $\begin{array}{l}\text { Lactic acid } \\
\text { g/l })\end{array}$ & $7.68 \pm 0.00^{\mathrm{c}}$ & $14.64 \pm 0.05^{\mathrm{b}}$ & $20.93 \pm 0.12^{\mathrm{a}}$ \\
$\begin{array}{l}\text { Increase } \\
\text { coefficient }\end{array}$ & $X$ & $1.91 X$ & $2.73 X$ \\
\hline
\end{tabular}

$\overline{\mathrm{a}, \mathrm{b}, \mathrm{c}, \mathrm{d}}$ Values with different letters on the same column differ significantly each other $(p<0.05)$. PM: production medium; PM-WNS: production medium without nitrogen source; PM-BC: production medium containing by-product from chicken as nitrogen source.

respectively. These LA concentrations are much important than the one obtained within the framework of our work. It was found that the production of LA would depend on nature and chemical composition of the carbohydrate and protein substrates in the fermentation broth and would also depend on the fermentation strain and fermentation conditions $[3,7,10,38]$.

In our study, the optimization of LA production led to an almost 1.43 -fold $(20.93 \pm 0.12 \mathrm{~g} / \mathrm{l})$ increase compared with the nonoptimized conditions. This value is not far from the one obtained with the nonoptimized conditions $(25.55 \pm 0.04 \mathrm{~g} / \mathrm{l})$ in our previous studies (Ngouénam et al. [10]) in which we used not only the same lactic ferment but also the same carbon source; however, nitrogen source was yeast extract. Thus, the difference between these LA concentrations may be due to the richness of yeast extract in group B vitamins as reported by Gomez-Gomez et al. [39].

\section{Conclusion}

By-products from fish, chicken, and beer brewing industries showed their ability to boost the growth of Lactiplantibacillus plantarum strain $4 \mathrm{O} 8$ and consequently the production of LA. By-products from fish and chicken were the most nutritious sources of nitrogen for the fermentation agent; however, by-products from chicken had the highest protein content. Temperature, nitrogen source (products from chicken), carbon source were the factors that influence the production of LA in the best production medium especially the one in which the nitrogen source was chicken byproducts. The optimization of the LA production in this medium allowed us to obtain an LA concentration of 20.93 $\pm 0.12 \mathrm{~g} / \mathrm{l}$. According to these results, chicken by-products are a potential nitrogen source that can be helpful in a large-scale production of LA. However, further studies should be oriented towards the use of these by-products for the lactic acid production in bioreactors, the purification of lactic acid present in the production medium, and the estimation of the percentage of lactic acid enantiomers.

\section{Data Availability}

No funding was obtained for this work.

\section{Conflicts of Interest}

The authors declare that they have no conflicts of interest.

\section{Acknowledgments}

We are grateful to M. Tambo Tene Stephano, M. Ulrich Daquain Fotso Techeu, M. Laverdure Piame Tchamani, and Miss Bilkissou Njapndounke for their contribution during writing, analysis, and discussion of the results.

\section{References}

[1] A. Olszewska-Widdrat, M. Alexandri, L.-G. Pablo, R. Schneider, M. Mandl, and J. Venus, "Production and purification of L-lactic acid in lab and pilot scales using sweet sorghum juice," Fermentation, vol. 5, no. 36, pp. 1-10, 2019.

[2] Y. Zhang and P. Vadlani, "Lactic acid production from biomass-derived sugars via cofermentation of Lactobacillus brevis and Lactobacillus plantarum," Journal of Bioscience and Bioengineering, vol. 20, no. 20, pp. 1-6, 2014.

[3] E. Abedi and S. Hashemi, "Lactic acid production-producing microorganisms and substrates sources-state of art," Heliyon, vol. 6, no. e04974, pp. 1-32, 2020.

[4] L. Coelho, C. De Lima, C. Rodovalho, M. Bernardo, and J. Contiero, "Lactic acid production by new Lactobacillus plantarum LMISM6 grown in molasses: optimization of medium composition," Brazilian Journal of Chemical Engineering, vol. 28, no. 1, pp. 27-36, 2011.

[5] M. Eiteman and S. Ramalingam, "Microbial production of lactic acid," Biotechnology Letters, vol. 37, pp. 955-972, 2015.

[6] R. Bayitse, "Lactic acid production from biomass: prospect for bioresidue utilization in Ghana: technological review," International journal of applied science and technology, vol. 5, no. 1, pp. 164-174, 2015.

[7] B. Krishna, G. Nikhilesh, B. Tarun, N. Saibaba, and R. Gopinadh, "Industrial production of lactic acid and its application," International Journal of Biotech Research, vol. 1, no. 1, pp. 42-54, 2018.

[8] F. Romelle, A. Rani, and Manohar, "Chemical composition of some selected fruit peels," European Journal of Food Science and Technology, vol. 4, no. 4, pp. 12-21, 2016.

[9] P. Kaktcham, E. M. Foko Kouam, M. L. Tchabou Tientcheu et al., "Nisin-producing_Lactococcus lactis_ subsp. _lactis_ 2MT isolated from freshwater Nile tilapia in Cameroon: bacteriocin screening, characterization, and optimization in a lowcost medium," LWT-Food Science and Technology, vol. 107, pp. 272-279, 2019.

[10] R. Ngouénam, K. C. Momo, P. Kaktcham, K. E. Foko, R. Maharjan, and N. F. Zambou, "Lactic acid production ability of Lactobacillus sp. from four tropical fruits using their byproducts as carbon source," Heliyon, vol. 7, no. e07079, pp. 110, 2021.

[11] P. Mudaliyar, L. Sharma, and C. Kulkarni, "Food waste management-lactic acid production by Lactobacillus species," International Journal of Advanced Biological Research, vol. 2, pp. 34-38, 2012.

[12] E. Mufidah and M. Wakayama, "Optimization of D-lactic acid production using unutilized biomass as substrates by multiple parallel fermentation," 3 Biotech, vol. 6, no. 186, pp. 2-8, 2016. 
[13] M. Umesh and K. Preethi, "Fermentative utilization of fruit peels waste for lactic acid production by Lactobacillus plantarum," Indian Journal of Applied Research, vol. 4, no. 9, pp. 449-451, 2014.

[14] X.-Y. Ge, Y. Xu, X. Chen, and L.-Y. Zhang, "Improvement of 1lactic acid production from orange peels in mixed culture system," Journal of Global Biosciences, vol. 3, no. 1, pp. 354-360, 2014.

[15] R. Kumar and S. Shivakumar, "Production of lactic acid from starch and food waste by amylotic Rhizopus orryzae MTCC8784," International Journal of ChemTech Reseach, vol. 6, no. 1, pp. 527-537, 2014

[16] M. Altaf, B. Naveena, and G. Reddy, "Screening of inexpensive nitrogen sources for production of $\mathrm{L}(+)$ lactic acid from starch by Amylolytic Lactobacillus amylophilus GV6 in single step fermentation," Journal of Food Technology and Biotechnology, vol. 43, no. 3, pp. 235-239, 2005.

[17] B. A. Moch, "Effect of nitrogen source and initial sugar concentration on lactic acid fermentation of pineapple waste using Lactobacillus delbrueckii," TEKNIK, vol. 31, no. 1, pp. 31-34, 2010.

[18] N. F. Zambou, D. V. Sieladie, A. Fonteh, P. Kaktcham, and M. El Soda, "Characterization and selection of lactobacilli with probiotic properties from cow's raw milk of "Bororo" cattle breeders in Dschang (Cameroon)," Current Research Journal of Biological Sciences, vol. 4, no. 2, pp. 143-152, 2012.

[19] R. F. Ben, F. Frikha, W. Kamoun, L. Belbahri, Y. Gargouri, and N. Miled, "Culture of Staphylococcus xylosus in fish processing by-product-based media for lipase production," Letters in Applied Microbiology, vol. 47, no. 6, pp. 549-554, 2008.

[20] O. Zarei, S. Dastmalchi, and M. Hamzeh-Mivehroud, "A simple and rapid protocol for producing yeast extract from Saccharomyces cerevisiae suitable for preparing bacterial culture media," Iranian Journal of Pharmaceutical Research, vol. 15, no. 4, pp. 907-913, 2016.

[21] IUPAC (International Union of Pure and Applied Chemistry), "Méthode d'analyse des matières grasses," International Digest of Health Legislation, vol. 46, no. 2, p. 241, 1979.

[22] AOAC, "Association of official analytical chemists," in Official methods of analysis, Dr. William Horwitz, Washington. DC, 13th edition, 1980.

[23] H. Herdian, L. Istiqomaha, E. Damayanti et al., "Isolation of cellulolytic lactic-acid bacteria from Mentok (Anasmoschata) gastro-intestinal tract," Tropical Animal Science Journal, vol. 41, no. 3, pp. 200-206, 2018.

[24] E. Fisher and E. Stein, "DNS colorimetric determination of available carbohydrates in foods," Biochemical Preparation, vol. 8, pp. 30-37, 1961.

[25] N. Borshchevskaya, T. Gordeeva, A. Kalinina, and S. Sineokii, "Spectrophotometric determination of lactic acid," Journal of Analytical Chemistry, vol. 71, no. 8, pp. 755-758, 2016.

[26] M. Kieliszek, K. Pobiega, K. Piwowarek, and A. Kot, "Characteristics of proteolytic enzymes produced by lactic acid bacteria," Molecules, vol. 26, no. 1858, pp. 1-15, 2021.

[27] R. Mouokeu, H. Womeni, N. F. Njike et al., "Chemical composition and antibacterial activity of oils from Chysicthys nigrodigitatus and Hepsetus odoe, two freshwater fishes from yabassi, Cameroon," Lipids in Health and Disease, vol. 17, no. 45, pp. 1-7, 2018.

[28] W. Pambuwa and J. Tanganyika, "Determination of chemical composition of normal indigenous chickens in Malawi," Inter- national Journal of Avian \& Wildlife Biology, vol. 2, no. 3, pp. 86-89, 2017.

[29] A. Nordhagen, A. Rizwan, I. Aakre et al., "Nutrient composition of demersal, pelagic, and mesopelagic fish species sampled off of Bangladesh and their potential contribution to food and nutrition security-the EAF-Nansen Programme," Food, vol. 9, no. 730, pp. 1-19, 2020.

[30] M. Pateiro, P. Munekata, R. Domínguez et al., "Nutritional profiling and the value of processing by-products from Gilthead Sea Bream (Sparus aurata)," Marine Drugs, vol. 18, no. 101, pp. 1-18, 2020.

[31] S. Abbasiliasi, J. S. Tan, T. A. Ibrahim et al., "Fermentation factors influencing the production of bacteriocins by lactic acid bacteria: a review," Royal Society of Chemistry Advances, vol. 7, pp. 29395-29420, 2017.

[32] A. Boudjelal and N. Nancib, "Production d'Acide Lactique par Lactobacillus Rhamnosus sur Milieu à Base de Jus de Dattes," Revue des Energies Renouvelables.:Production et ValorisationBiomasse, pp. 41-46, 2001.

[33] J. Mora-Villalobos, J. Montero-Zamora, N. Barboza et al., "Multi-product lactic acid bacteria fermentations: a review," Fermentation, vol. 6, no. 23, pp. 1-21, 2020.

[34] H. Myers, C. Douglas, and M. Christine, Response surface methodology; process and product optimization using designed experiment, Wily, 2009.

[35] J. M. Klang, S.-L. Wouatidem-Nanfack, S. T. Tene, G. T. Boungo, and H. M. Womeni, "Optimization of the production of corn amylase flour from corn Atp and Kassai varieties for the fluidification and energy density increase of cassava gruel," Heliyon, vol. 6, no. e05344, pp. 1-12, 2020.

[36] S. Costa, D. Summa, B. Semeraro, F. Zappaterra, I. Rugiero, and E. Tamburini, "Fermentation as a strategy for biotransforming waste into resources: lactic acid production from agri-food residues," Fermentation, vol. 7, no. 3, pp. 1-12, 2021.

[37] H. Azaizeh, H. Tayeh, R. Schneider, A. Klongklaew, and J. Venus, "Production of lactic acid from carob, banana and sugarcane lignocellulose biomass," Molecules, vol. 25, no. 2956, pp. 1-14, 2020.

[38] A. Komesu, J. A. R. de Oliveira, L. Martins, M. R. Wolf Maciel, and R. Maciel Filho, "Lactic acid production to purification: a review," BioResources, vol. 12, no. 2, pp. 4364-4383, 2017.

[39] J. Gomez-Gomez, C. Girlado-Estrada, D. Habeyech, and S. Baena, "Evaluation of biological production of lactic acid in a synthetic medium and in Aloe vera (L.) Burm.f. processing by-products," Universitas Scientiarum, vol. 20, no. 3, pp. 369385, 2015. 